\title{
PROMOTING POSITIVE MENTAL HEALTH IN INTERNATIONAL POSTGRADUATE LAW STUDENTS AT A TIME OF GLOBAL UNCERTAINTY: A CASE STUDY FROM QLEGAL AT QUEEN MARY, UNIVERSITY OF LONDON
}

Emily Wapples ${ }^{1}$

\section{Abstract}

Law student mental health and wellbeing was already a growing concern in the UK prior to COVID-19, but when the pandemic occurred, widespread uncertainty placed an unprecedented level of mental health burden on students. Law students were faced with dashed hopes, uncertain futures and the fear of negative academic consequences. This burden was exacerbated in respect of postgraduate international students in London, who were often also forced to decide whether to return home to their families, or to continue their studies abroad, albeit online.

This paper uses a case study approach to discuss how one provider of postgraduate clinical legal education (CLE), approached the promotion of positive student mental health both before, and in response to, the pandemic. qLegal at Queen Mary, University of London provides CLE to postgraduates studying for a one year law masters, and in 2019-2020, qLegal delivered CLE to 134 students from 27 countries. 
The impact that the pandemic had on the mental health of international postgraduate law students was therefore witnessed first-hand.

This paper discusses the challenges faced, and concerns raised by international postgraduate law students at qLegal as a result of the pandemic. It examines the steps taken by qLegal to maximise student engagement and promote positive student mental health when rapidly switching to a model of online delivery. The paper concludes by outlining the steps qLegal will take to monitor and address the impact that online delivery in this period of global uncertainty has on the mental health of the next cohort of postgraduate CLE students.

\section{Introduction}

Law student mental health and wellbeing was already a growing concern in the UK prior to the COVID-19 pandemic (the 'Pandemic'). The global uncertainty resulting from recent events has exacerbated these concerns and placed an unprecedented level of mental health burden on students, especially those studying internationally.

This paper adopts a case study approach to discuss how qLegal, the pro bono commercial law clinic within the Centre for Commercial Law Studies at Queen Mary, University of London ('QMUL') approached the promotion of positive student mental health both before, and in response to, the Pandemic. It discusses the challenges faced by qLegal and our students in the wake of the Pandemic, and reflects on the steps 
taken to maximise student engagement and promote positive student mental health when rapidly switching to a model of online delivery of clinical legal education ('CLE').

This paper aims to highlight the urgent need for CLE providers to integrate the promotion of positive student mental health into their online offerings and provides suggestions for ways to do so. As a result, it is hoped that we can equip law students with the emotional intelligence and skills they need to meet their potential in an increasingly demanding profession.

Before discussing the impact of the Pandemic on our students, it is necessary to first set the scene by discussing qLegal's CLE offering, the concerns which international students faced prior to the Pandemic, and our approach to student mental health generally.

\section{PART 1: CONTEXT}

\section{What is qLegal?}

Now in its seventh year, qLegal operates as a simulation of an innovative commercial law firm. It offers pro bono legal advice and support to start-ups and entrepreneurs in areas such as intellectual property law, data protection, corporate structure and commercial contracts. qLegal students have the opportunity to participate in its 
programmes either in addition to their studies, or as an assessed, credit-bearing module. In 2019-2020, student programmes included (for example):

1. Legal advice clinic: Under the supervision of a qualified lawyer, student advisers interview clients, undertake research, and provide tailored preliminary written advice to clients.

2. Public Legal Education ('PLE'): Students research, prepare and deliver workshops, or draft toolkits to raise legal and business awareness in schools, and among the start-up community. This includes qLegal's Street Law and Business initiative ('StreetLaB'), where students design and deliver lessons on law and entrepreneurship to pupils in disadvantaged areas, culminating in an incubatorstyle 'Pitch It' competition for the pupils, run with external lawyers.

3. Legal Design: In teams, students use Legal Design methodology to produce solutions to law-related problems.

Together, the qLegal programmes aim to equip postgraduate law students with the legal and practical skills they need to succeed as lawyers in the $21^{\text {st }}$ century: skills which legal employers often regard junior lawyers as lacking, such as commerciality and client care ${ }^{2}$.

2 BPP University Law School (2018), The law training report: What skills do firms expect new entrants to possess in the post SQE era?, pp.18-22 [online] available at https://s3-eu-west1.amazonaws.com/bppassets/public/assets/pdf/brochures/Uni-Law-SQE-Focus-Groups-Report2018.PDF 
Practice Report

In 2019-2020, the qLegal team comprised three full-time and one part-time employees with diverse backgrounds spanning CLE, legal practice, entrepreneurship, coaching and project management ${ }^{3}$. Two of the employees are also trained as Mental Health First Aiders ${ }^{4}$.

\section{London: the student capital of the world}

In 2019, London was ranked as the number one city in the world for students 5 . Students are attracted to the excellent academic offerings; diverse nature of the city and the employment prospects London brings (among other things) ${ }^{6}$. QMUL offers a truly international experience for students, achieving $18^{\text {th }}$ place in the 2018 Times Higher Education international students table, with $44.8 \%$ of its students coming from abroad $^{7}$. In 2019-2020, qLegal provided CLE to 134 postgraduate students from 27 countries studying for a one year law masters. The countries with the highest number of qLegal applicants were India, China, Italy and Greece, with students regularly

\footnotetext{
3 http://qlegal.qmul.ac.uk/about/team/

4 The Mental Health First Aid ("MHFA") programme began in Australia in 2000, and has since evolved into a global movement that is delivered by an active community of licensed providers in 24 countries. MHFA training first came to England in 2007, and between 2018-2019 MHFA England trained over 140,000 people in mental health skills. MHFA England (2018-2019), MHFA England Impact Report 2018-2019, p.1 and p.9 [online] available at https://issuu.com/mhfaengland/docs/mhfa_england_impact_report_2019/2?ff

5 QS Quacquarelli Symonds (2019), Rankings Revealed: The Best Student Cities of 2019 [online] available at https://www.qs.com/rankings-revealed-the-best-student-cities-2019/

6QS Quacquarelli Symonds (2020), QS Top Universities - London [online] available at https://www.topuniversities.com/university-rankings-articles/qs-best-student-cities/london

7Times Higher Education (2018), The World University Rankings. International student table 2018: top 200 universities [online] available at https://www.timeshighereducation.com/student/bestuniversities/international-student-table-2018-top-200-universities
} 
citing a desire to gain practical experience of the London legal market as their motivation for applying.

\section{Concerns of international students}

It is acknowledged that international students frequently have additional concerns to domestic students, including being away from friends and family, learning different study methods and learning in a new language ${ }^{8}$. QMUL students complete their Law Masters in one year; a third of the time law students spend studying for their undergraduate degrees. The process of adjusting to their new studies and environment, and forming new friendship and support groups is therefore accelerated and intensified for international postgraduate law students.

qLegal's approach to teaching and pastoral support has been developed, and continues to be refined to address the additional concerns that our international students commonly face.

\section{Law student mental health}

It is acknowledged that "law student mental health and wellbeing is a growing concern in the $\mathrm{UK}^{\prime \prime 9}$ (LawCare, n.d.). This paper adopts the following definitions and understanding of mental health:

\footnotetext{
8 UK Council for International Student Affairs (2020), Mental health support in the UK, [online] available at https:/www.ukcisa.org.uk/Information--Advice/Studying--living-in-the-UK/Mentalhealth-support-in-the-UK

9 LawCare (date unknown), Wellbeing in Law Teachers \& Students Workshop [online] available at https://www.lawcare.org.uk/news/wellbeing-in-law-teachers-students-workshop
} 
"Mental health is a state of wellbeing, in which an individual realizes his or her own abilities, can cope with the normal stresses of life, can work productively and is able to make a contribution to his or her community"10 (World Health Organization, 2019).

Mental health can be "seen as a continuum, ranging from having good mental health to poor mental health and from having no diagnosis of mental illness to a diagnosis of severe mental illness"11 (MHFA England, 2016).

People become ill when the stress they face becomes more than they can cope with ${ }^{12}$.

qLegal's approach to student mental health prior to the Pandemic

Appleby and Bourke (2014) assert that law students are a particularly 'at risk' group of mental ill health, stating that "[m]any law students experience elevated levels of emotional distress during their time at law school...[which]...are statistically significant predictors of serious mental illnesses"13. In our experience, postgraduate

10 World Health Organization (2019), Mental Health: Fact Sheet, p.1 [online] available at https://www.euro.who.int/_data/assets/pdf_file/0004/404851/MNH_FactSheet_ENG.pdf

11 MHFA England (2016), Adult MHFA Manual (publisher unknown), p.32.

12 Ibid 11 p.44. The 'Stress Vulnerability Model' was "proposed by Zubin and Spring in 1977. The idea behind it is that people become ill when the stress they face becomes more than they can cope with. Also, people's ability to deal with stress - their vulnerability - varies, so problems which one person may take in their stride might be enough to cause another person to become depressed or develop other mental health issues...".

13 Appleby, M. and Bourke, J. (2014), Promoting Law Student Mental Health Literacy and Wellbeing: A Case Study from The College of Law, Australia, IJCLE Vol 20, No 1 (2014), p.494 [online] available at https://www.northumbriajournals.co.uk/index.php/ijcle/article/view/18 
law students may experience heightened levels of emotional distress in situations when they feel lacking in control, do not have a good support network or feel isolated, and are placing unreasonable expectations on themselves. We recognise that students' ability to deal with these potentially stressful situations varies; situations which one student may be able to take in their stride, may cause another student to develop a diagnosable mental health condition.

qLegal aims to prepare students for real life and we understand that "working as a law professional can be very stressful, with overwhelming workloads and emotionally challenging cases"14. We expect our students to meet the same high standards they would in legal practice, but we are cognisant that many students may not be prepared for the additional pressures this brings. It is a difficult balance to strike. We do not shield students from the demands of legal practice in the UK, but equip them with the tools to be able to thrive within it.

Specific techniques used to promote positive student mental health

Promoting positive student mental health and wellbeing has always been an important focus for qLegal, and two team members are trained Mental Health First Aiders. Our mental health strategy involves addressing the topic consistently throughout the programmes and embedding it within the student experience.

14 The Law Society (n.d.), Stress and mental health [online] available at https://www.lawsociety.org.uk/career-advice/career-development/stress-and-mental-health 
The commitment to the promotion of positive student mental health for our 2019-2020 cohort began at the student induction day; the focus of the event being mental health in the legal profession. The aim was to destigmatise the topic by addressing it headon.

At the beginning of the year, students were given 'Journey Guides' and asked to reflect on and record how they were feeling about their goals, skills and the way they worked (among other things). They were then encouraged to review these at the end of the programmes, to consider the ways in which they had developed as a result of their qLegal experience. This process of reflection helps students to develop self-awareness and encourages them to take responsibility for their development, which in turn, nurtures their emotional intelligence.

Emotional intelligence and resilience are often cited as skills which employers consider valuable in junior lawyers ${ }^{15}$. Our students are therefore encouraged to develop their resilience and their ability to adapt to new and unforeseen circumstances, or to cope with setbacks and frustrations. Again, this concept is peppered throughout the qLegal training programme ${ }^{16}$.

Students received extensive training on how to give and receive feedback, and were encouraged to adopt a peer coaching approach to problem solving. By discussing

15 Ibid 2, p.17.

16 For example, the qLegal Manifesto which students have to agree to at their induction provides that "[students] agree to welcome constructive feedback and provide it when it is asked of [them]...[students] cultivate resilience by trying [their] best, and letting [themselves] be seen". 
unforeseen problems or setbacks with their peers, students were able to form solid support networks with one another.

Coupled with these formal approaches to learning and development, care and attention has been paid to developing the 'qLegal student experience'; that added social and emotional connection students feel with qLegal and their peers. "A positive student experience is defined by a high quality, modern teaching experience in an environment where students are made to feel safe and welcomed"17. The message that 'qLegal is a big family' and that everyone has something to contribute to it is constantly reinforced during the programmes, and after graduation with our alumni network.

Building on this, students were told to treat each other, and qLegal as colleagues. They were encouraged to shift their mind-set from seeing qLegal as part of their academic studies, to seeing it as an opportunity to gain real life, practical experience of the London legal market. Students were held to high professional standards and were accountable to each other. qLegal modelled the professional behaviour we expected students to adopt. We knew that their qLegal experience may be challenging at times, but we wanted to give students an insight into the pressures of legal practice within the safe and supportive qLegal environment. 
Finally, the requirement for students to conduct their confidential case work in the qLegal office facilitated, albeit indirectly, the opportunity for students to interact with others on their programme and the qLegal team on an informal basis. We also operated an 'open door policy' during business hours. These serendipitous encounters contributed to a greater sense of inclusion and the creation of a collegiate atmosphere among students and the team.

Together, these initiatives aimed to equip students with the professional, personal and emotional skills necessary to succeed in their future careers. By educating students on the importance of developing self-awareness, emotional intelligence and resilience, and encouraging them to form good support networks with their peers, students were better placed to thrive when placed under pressure.

PART 2: The challenges faced, and concerns raised by qLegal's students as a result of the pandemic

\section{Homeward bound: qLegal's immediate response to the pandemic}

In line with government guidelines for academic institutions, all qLegal operations were taken online from $17^{\text {th }}$ March 2020. In the preceding weeks, our international students frequently shared their concerns with us. Students were often worried about family members back home, they were upset that people in the UK were not taking 
the situation seriously enough, and were concerned that they may not make it to their home countries before international borders closed.

The increasing levels of uncertainty placed greater emotional burdens on our students. Mindful of this, qLegal began to formulate our response to the Pandemic. In doing so, we were conscious of the need to provide students with regular, clear communication confirming what was happening, and what we expected of them. We acknowledged the uncertain times and encouraged students to remain positive and upbeat, so far as possible.

Our response required significant flexibility and creative thinking on the part of both qLegal and our students. Two illustrative examples of the approach taken to facilitate the remainder of the activities, and the challenges faced as a result will be discussed before turning to the challenges faced more generally by qLegal students.

\section{PLE/StreetLaB Students}

Students had delivered lessons to pupils in two local schools for two semesters, which would culminate in a 'Pitch It' competition between the schools. The grand finale was due to take place in early March, at the City offices of a global organisation, in front of external judges. However, the organisation's internal Pandemic policy prevented them from hosting the event. An alternative venue could not be sourced in time, due to the schools' internal policy for obtaining advanced parental/guardian consent to any off-site activities. 
The solution adopted was to run two separate competitions; one at each school. Pupils would compete only against their fellow students, in front of a panel of qLegal judges. All qLegal StreetLaB students attended both competitions.

There was widespread uncertainty in the UK regarding how organisations and individuals should be responding to the Pandemic, and guidance from the government, within QMUL, and within our external partners often changed with very little notice. Consequently, the logistics for the event were only finalised in the days immediately preceding the competition. The uncertainty of whether the competition would take place (and if so, how) was a key concern for our students. Knowing that students respond well to structure and routine, we increased the frequency of our communications with them. We organised additional in-person meetings and updated students regularly by email on the state of play.

A big draw to the StreetLaB programme for qLegal students was the opportunity to attend the offices of the global organisation for the competition. Students were disappointed at no longer being able to do so. We were conscious that these dashed hopes could lead to a general lack of motivation and feelings of failure for students. We addressed this in two ways: (1) by qLegal remaining positive and upbeat about the event, hoping that students would begin to mirror our behaviour; and (2) by encouraging the students to re-frame the Pandemic as an opportunity to demonstrate their adaptability and resilience, skills which employers often consider lacking in junior lawyers. 
Practice Report

\section{Legal Design Students}

Legal Design is a methodology used by law firms to innovate, and put clients, and ultimate end-users, at the heart of legal service delivery. It is built on empathy and requires lawyers to research and create personas of the end-users, before designing and testing prototype solutions to meet end-users' needs. The idea is that law should not be delivered in a way that only suits other lawyers.

Students had been working for the whole semester to prepare for their second Legal Design challenge, which required them to use design thinking methodology to redesign the qLegal Legal Design programme. In teams, they would pitch their ideas to a panel of external judges and the winning idea will be implemented by qLegal next year. The pitch was due to take place in late March, after the lockdown began in the UK. Consequently, the competition took place remotely, with a mixture of external and qLegal judges.

Again, the students were disappointed that the competition could not take place in the circumstances they had initially envisaged. In response, we were keen to ensure that the online event had a real sense of occasion to it and reiterated to students just how seriously the judges were taking their responsibilities.

The students rose to the challenge, despite the difficulties they faced during this time. The majority of the international students had returned home before the competition took place. Further, at the time of the competition, one student had been admitted to hospital in India, and another was in self-isolation in Kenya. Notwithstanding this, 
the teams agreed that they all wanted to participate in the finale, and students from India, Russia, Cyprus and Kenya all pulled together to deliver their pitches. The students' enthusiasm and commitment to finishing their programme was a testament to their resilience.

\section{Challenges and concerns across all qLegal programmes}

In addition to the specific challenges faced by students on these two programmes, there were a number of difficulties which were experienced by students across all programmes. Foreseeing that these issues could be of great concern to students, we were keen to adopt an empathetic, yet professional manner when communicating with students. These challenges faced by students across all programmes fell broadly into two categories.

\section{Availability issues}

Although in theory the adoption of technology gave students the ability to work anytime, anywhere, the requirement that students worked in teams to complete their work often created challenges when working remotely.

Some students were unavailable to work on their case for up to 48 hours as they made the journey back to their home country. Other international students stayed in London but changed their living arrangements. Consequently, these students often found their study routine disrupted by their newfound family commitments. 
Anticipating that the availability of their teammates and coordinating work across time-zones may have proved frustrating for some students, we were keen to encourage students to be understanding of each other's circumstances and exercise patience. Although qLegal expects students to meet their deadlines, a degree of flexibility was displayed, especially to students on the Legal Advisory programme (who worked in pairs, meaning the unavailability of one student placed a heavier workload burden on the other).

\section{Technology issues}

Despite frequently being described as 'digital natives' because of their familiarity with, and access to, technology, some students still experienced occasional difficulties using the new platforms adopted. Unreliable internet connections often prohibited the use of cameras on video calls. Further, some students appeared hesitant, at least at first, to use their camera when attending calls with us: finding this new experience a little daunting.

Again, we encouraged students to be patient with each other, and qLegal while we all familiarised ourselves with the new technology. We shared the difficulties we had experienced in an attempt to demonstrate that we were 'all in this together' as part of a larger qLegal team.

\section{Additional concerns raised by international students}




\section{Practice Report}

The global nature of the health crisis meant that students' concerns for family members in other parts of the world began long before the UK lockdown. Students began confiding in the qLegal team about their concerns for family members back home and began making arrangements to return to their home countries before the government closed international borders. The practicalities involved in securing their return home played on the minds of many students.

But the decision whether or not to return to their home country was not always an easy one. Students were often conflicted. Some students were keen to finish the year in London, gaining as much exposure to the local culture and employers as possible. Others continued to embrace the collegiate environment fostered by qLegal and its students, not wanting their academic and social experience to fizzle out when their fellow students began to leave campus. There was clear tension between the pull to return home, and the desire to remain in London until the end of term.

Whether students remained in London or returned home, they experienced a shakeup in their network of friends and support. With their fellow students relocating with little warning, students often found themselves without a nearby support network, at least in the days immediately following the $17^{\text {th }}$ March.

qLegal check-in sessions

One international student (who had chosen to stay in London) confided that they were finding things more difficult given the lack of contact they were having with their fellow students, as many close friends were now abroad. They also noted that they 
did not want to approach tutors and academic staff to discuss the course and next steps generally, for fear of "being a burden".

In response, we introduced informal online check-in sessions for students with a member of the qLegal team. The optional sessions ran three days a week between May and July 2020. The aim was to give students the opportunity to talk to a member of the team in a confidential, but informal setting; whether about their programmes, careers, or just to tell us how they were spending their time. Sessions were drop-in, on a first-come basis, for 15 minutes and took place using Microsoft Teams.

Student take-up of the check-in sessions was lower than anticipated. Possible explanations could reasonably include: students' attention already being elsewhere (such as on their dissertation or employment); availability issues; or lack of promotion of the sessions. The students who did use the service appeared to find it useful, occasionally having a further check-in with another member of the team a few weeks later.

The time commitment involved in organising and attending the check-in sessions was minimal and despite the small take up from students, the initiative was considered a success and will be repeated next year.

\section{Concerns shared with domestic students}

International students also shared a number of additional concerns with domestic students, the most pressing one being the impact that the Pandemic would have on 
their academic achievements and career prospects. The removal of the structure and routine that classroom-based learning provides students, along with the increased requirement for students to learn independently were also concerns for all students. To combat this, we increased the frequency of our communications with students, ensuring that clear instructions were given regarding the opportunities available to, and responsibilities placed on students.

\section{Reflections on our experience}

The Pandemic placed a greater emotional burden on all students. Widespread uncertainty caused students to feel a lack of control, cancelled in-person events led to dashed hopes, and difficulties using new technology to communicate with teammates across time-zones proved frustrating.

Our strategy to minimise the effect that these concerns could have on our students was two-fold. Firstly, we increased the level of communication we had with students, making sure we communicated our instructions and expectations clearly and offering additional opportunities to meet with students online. Secondly, we always remained upbeat and encouraged students to re-frame the Pandemic as an excellent opportunity for them to demonstrate their adaptability and resilience.

PART 3: Maximising student engagement and promoting positive student mental health in an online classroom environment 
Practice Report

\section{What we did}

The Legal Design and StreetLaB competitions were stand-alone events involving students on specific programmes. When the Pandemic hit, two further (optional) programme-wide opportunities were outstanding: (1) a CV workshop: training students how to make the most of their qLegal experience on their CV; and (2) the graduation ceremony: where students celebrated their qLegal successes and began the transition to qLegal alumni.

We decided early on that the students should not miss out on these opportunities and that we would offer them online ${ }^{18}$. However, we knew that just having the technology in place to facilitate online learning would not be enough, and careful consideration was given to how we would encourage students to engage with the technology and opportunities provided. We curated the events with a view to maximising student engagement and interaction.

The events took place in early June, at times of the day which would accommodate maximum numbers of students across various time-zones. Of the 134 students on our programmes, 18 students attended the $C V$ workshop and 24 the graduation ceremony. Of the students who did attend, the vast majority were international students, many of whom had returned to their home country but were keen to see and interact with their fellow students again. We asked students to confirm where they were joining

18 We used Blackboard Collaborate, a virtual classroom solution. 
from, which broke the ice and demonstrated the global nature of their student network and the ability of technology to bridge global borders, thereby allowing students to feel a sense of connection to each other.

Specific care and attention was given to ensuring that the graduation ceremony was viewed as, and felt like a party; and not simply another webinar. We provided students with clear instructions about the event; setting the agenda and our expectations of them. To create a sense of occasion, students were encouraged to 'dress up' and have a drink close by to toast their cohort. Students really embraced the positive and playful tone of the event, and our preparations paid dividends. Feedback we received from students regularly cited the personal celebration of the achievements of each student as a significant factor in making the event "enjoyable and memorable", allowing students to end their experience on a high.

\section{Reflections on our experience}

Creating and delivering an engaging online CLE learning environment takes a lot of effort. The way in which all aspects of the qLegal programmes were delivered was reexamined and re-imagined, to ensure that students were still being given the best possible experience online.

The online learning experience can feel dehumanising and isolating to students. It is important to engage with students meaningfully and to encourage them to bring aspects of their personality to the session. For example, at the graduation, students 
were asked to share answers to personal questions such as 'who do they look up to?'. This was done to encourage students to bond in this new online environment.

Less is more when it comes to the length and frequency of online learning activities: our sessions were capped at 90 minutes, with a short screen break. Each session was curated to meaningfully add to the students' development, and sessions were well structured and interactive. They included small group discussions, practical exercises and made full use of the instant messaging facility. The aim was to build students' trust, and ultimately their engagement in the online learning process.

If students had initially been hesitant to speak on camera at the start of the Pandemic, or saw technology as a barrier to natural discussion, they were now more open to, and confident using their cameras. The possible perceived safety of being behind a computer screen gave some students increased confidence to contribute to group discussions. We noticed that certain international students whose behaviour had been extremely professional and reserved throughout their experience now displayed more playful and personable attributes.

In these times of instability and uncertainty, students have greater independence over their studies and how they spend their time. The purpose and benefits of each online event must be clearly publicised in advance to encourage and maximise attendance. The low attendance rate at the CV workshop and graduation ceremony was disappointing and suggests a shift in behaviour by students, who were under increased pressure and wanted to focus on their credit bearing modules rather than 
their extracurricular activities. In future, extra effort will be made to clearly advertise the benefits that students will obtain by attending optional online events.

The ideas and techniques adopted in these examples were not novel; it is anticipated many, if not all, were being adopted by CLE providers across the world. However, what made them a success was the effort we made in ensuring that the teaching was deployed with care; in a personal, individualistic way.

When curating the online events, we were conscious to continually provide students with sufficient information and opportunities to help them regain control over their studies. We remained upbeat throughout and encouraged students to do the same. It was hoped that if students felt positive about their studies and secure within their support networks, they would be better placed to deal with the increased pressure caused by the Pandemic.

PART 4: Steps qLegal will take to monitor and address the impact that postpandemic online delivery has on students

Having worked with international postgraduate law students for the past six years, qLegal has a good understanding of the needs of our students and the specific concerns they have over and above many domestic ones. The focus on delivering the 'qLegal student experience', and a holistic approach to student development, breaks down cultural barriers, and builds cohorts of close-knit students armed with the 
practical skills and emotional intelligence needed when entering the legal job market. This, coupled with a shared desire for constant innovation and growth, makes qLegal well placed to adapt its offerings, where necessary, to meet the needs of students in this Pandemic era.

The steps we will take in the 2020-2021 academic year to monitor and address the Pandemic's impact on student mental health fall into three broad categories.

\section{Building online engagement}

As with many, if not all other CLE providers, qLegal will deliver CLE using blended learning in the 2020-2021 academic year, combining online and in-person activities.

We will deliver CLE using a flipped classroom approach. Students will be expected to watch training videos introducing them to the topics, and will then attend live webinars where they can discuss those topics in more detail with qLegal and their peers.

The techniques used to deliver quality, personal online learning opportunities to CLE students last year will continue to be deployed across programmes. In doing so, it is anticipated that students will be proactively encouraged "to become fully invested in the online learning experience and to enthusiastically embrace it as a crucial component of their higher education experience"19 (QS Quacquarelli Symonds, 2020).

19 QS Quacquarelli Symonds (2020), QS Stars Rating System - How to access your university's online learning capabilities (2020) p.10 [online] available at https://www.qs.com/portfolio-items/how-toassess-your-universitys-online-learning-capabilities/ 


\section{Building resilience and positive wellbeing}

Mental health education and support will continue to be embedded throughout the programmes largely in the manner adopted previously. Additional training and guidance will be provided on how to stay safe online and the potential detrimental impact overusing technology can have on mental health and wellbeing.

As part of the reflective journal students are required to keep, students will be asked to complete a short (anonymous) survey recording how they feel about the future, the support they are receiving from the qLegal team and peers, and their attitudes towards online learning (among other things). The survey will be completed at the start and end of the academic year for students to monitor their progress during the programme. The results will also be used by qLegal to assess the effectiveness of the offering to students, specifically in the context of online delivery.

The drop-in, confidential check-in sessions will be offered in the format trialled earlier this year, but with increased publicity to students at the start of the year.

\section{Building student networks}

To compensate for the lack of in-person opportunities students will have to socialise with each other, qLegal will host additional weekly online events for students across all programmes. Students with a live case or PLE project will be required to attend weekly breakfast meetings. They will reflect on, and share their experience on their cases, thereby encouraging a peer coaching approach to student development. In 
doing so, students will expand their friendship and support network, and gain a sense of ownership and belonging within the qLegal community.

All students will also have the option of joining an informal online 'qLegal Friday social'. Students and the qLegal team will share photographs of themselves as a baby and will compete to guess who each photo belongs to. They will be encouraged to show their fellow students an object which says something about their personality and contribute a recipe for inclusion in a qLegal international recipe book. The aim of these activities is to encourage students to really get to know one another and to build a collegiate atmosphere.

Neither of these scheduled events will make up for the serendipitous nature of students running in to one another in the qLegal office. However, they are a way of encouraging students to build their personal friendship and support networks and to feel part of qLegal, with the ultimate aim of preventing student isolation.

\section{Conclusion}

It is clear that the Pandemic has placed unprecedented levels of mental health burden on all students, not just international ones studying postgraduate law. Students are faced with a new way of learning, uncertain futures and increased pressures. International students also experience additional concerns as a result of being away from home and learning in a new language. 
If these pressures become greater than an individual can cope with, they have the ability to trigger a diagnosable mental illness. Accordingly, it is important that steps are taken to minimise these pressures, and simultaneously increase students' ability to cope in times of extreme pressure, thereby seeking to prevent the occurrence of mental ill health.

The initiatives qLegal adopt have the dual aims of delivering quality CLE programmes to postgraduate students, and facilitating their personal, professional and emotional development. We equip students with the skills and resilience to adapt to these unprecedented times. Extra care will be taken to provide clear and bounded instructions for students, to develop a structure and routine around the online learning environment. Students will be encouraged to build their own support networks and adopt a peer coaching approach to problem solving. Finally, qLegal will continue to promote the Pandemic as an opportunity for students to demonstrate their adaptability and ability to persevere in the face of adversity.

None of these ideas may, of themselves, seem novel or significant. However, by deploying these ideas consistently throughout the qLegal programmes, it is hoped that students will experience a reduction in the external pressures they face, while simultaneously developing an increasing tolerance to such pressure. As a result, students will be better placed to thrive in the highly demanding legal profession. We would encourage other providers of CLE to consider the ways in which they can also 
encourage their students to thrive within this increasingly uncertain and pressurised environment.

It is also important to remember that these unprecedented times bring uncertainty for everyone. Although the strategies and initiatives discussed in this paper may reflect our current conclusions on the best way forward for delivering CLE to our 2020-2021 cohort, all students offerings should remain flexible and adaptable, being tailored to the specific needs of the students at any given point in time. qLegal will have open channels of communication with students and will welcome feedback on the manner in which they are taught, with offerings constantly reviewed and updated to better suit the present needs of our students. We would encourage other CLE providers to do the same. 